\begin{abstract}
AS MANIFESTAÇÕES DE JUNHO DE 2013, O PROCESSO DE CONSTRUÇÃO DOS DIREITOS DE CIDADANIA NO BRASIL E O DIREITO À CIDADE.
\end{abstract}

\author{
THE 2013 PROTESTS, THE CITIZENSHIP RIGHTS CONSTRUCTION PROCESS IN BRAZIL \\ AND THE RIGHT TO THE CITY.
}

Grupo de Pesquisa em Direito Urbanístico da Fundação Escola Superior do Ministério Público do Rio Grande do Sul Betânia de Moraes Alfonsin - Coordenadora ${ }^{1}$ Fernanda Peixoto Goldenfum²

Aline Rocha ${ }^{3}$

Bruno Siufi ${ }^{4}$ Giani Camargo Cazanova ${ }^{5}$ Livia Ribeiro ${ }^{6}$ Mariana Vivian ${ }^{7}$ Viviane Guimarães ${ }^{8}$

\footnotetext{
${ }^{1}$ Doutora em Planejamento Urbano e Regional pelo Instituto de Pesquisa e Planejamento Urbano (IPPUR) da UFRJ. Atualmente é professora da Fundação Escola Superior do Ministério Público do RS, onde desempenha também a coordenação das atividades complementares da instituição. É ainda professora da Pontifícia Universidade Católica do Rio Grande do Sul, vinculada ao Departamento de Direito Público. Atua como professora de Educação à Distância no Curso de Dimensiones Jurídicas de la Política Urbana e no Programa para America Latina y el Caribe do Lincoln Institute of Land Policy. Email: betania@via-rs.net.

${ }^{2}$ Pós-graduanda em Direito Municipal pela Escola Superior de Direito Municipal/Fundação Escola Superior do Ministério Público - FMP, integrante do Grupo de Pesquisa em Direito Urbanístico da Fundação Escola Superior do Ministério Público do RS.

${ }^{3}$ Graduanda em Direito, PUCRS. Integrante do Grupo de Pesquisa em Direito Urbanístico da Fundação Escola Superior do Ministério Público do RS.

${ }^{4}$ Graduando em Direito, Fundação Escola Superior do Ministério Público - FMP. Integrante do Grupo de Pesquisa em Direito Urbanístico da Fundação Escola Superior do Ministério Público do RS.

${ }^{5}$ Pós-graduanda em Direito Municipal pela Escola Superior de Direito Municipal/Fundação Escola Superior do Ministério Público - FMP. Integrante do Grupo de Pesquisa em Direito Urbanístico da Fundação Escola Superior do Ministério Público do RS.

${ }^{6}$ Graduanda em Direito na Universidade Federal do Rio Grande do Sul. Integrante do Grupo de Pesquisa em Direito Urbanístico da Fundação Escola Superior do Ministério Público do RS.

${ }^{7}$ Graduanda em Direito na Universidade Federal do Rio Grande do Sul. Integrante do Grupo de Pesquisa em Direito Urbanístico da Fundação Escola Superior do Ministério Público do RS.

${ }^{8}$ Pós-graduanda em Direito Ambiental na Universidade do Sul de Santa Catarina. Integrante do Grupo de Pesquisa em Direito Urbanístico da Fundação Escola Superior do Ministério Público do RS.
} 


\title{
Resumo
}

O artigo apresenta os resultados da análise empreendida pelo Grupo de Pesquisa em Direito Urbanístico da Faculdade de Direito da FMP sobre as manifestações de rua ocorridas no Brasil em junho de 2013. O objeto de pesquisa foi estudado a partir do tripé analítico composto pelos eixos (i) manifestações de 2013, (II) processo histórico de construção dos direitos de cidadania no Brasil e (iii) direito à cidade. Procurando articular os elos entre conjuntura e estrutura, o estudo de caráter interdisciplinar conclui que as manifestações de 2013 não foram um episódio isolado na história do país, mas, pelo contrário, ocupam um lugar significativo no processo de construção dos direitos de cidadania no Brasil e, além disso, deixam significativo legado político, cultural e simbólico. Tais acontecimentos imbricam-se com a emergência do direito à cidade, compreendido como direito coletivo dos habitantes de territórios urbanos, como pauta de reivindicação de distintos movimentos sociais urbanos, atores sociais e sujeitos coletivos engajados na democratização dos bens materiais e simbólicos produzidos e vivenciados nas cidades.

Palavras chave: Direito à Cidade. Cidadania. Manifestações. Funções sociais da cidade. Direitos fundamentais.

\begin{abstract}
The article presents the results of the analysis undertaken by the Urban Law Research Group of FMP of the Law School about the street demonstrations that took place in Brazil in June 2013. The research subject was studied from the analytical tripod composed by the following axis: (i) 2013 riots, (II) historical process of citizenship rights construction in Brazil and (iii) the right to the city. Trying to articulate the links between conjuncture and structure, the interdisciplinary study concludes that the riots of 2013 were not an isolated episode in the history of the country, but in fact, occupies a significant place in the construction of citizenship rights in Brazil and also leaves significant political, cultural and symbolic legacy. Such events are intertwined with the emergence of the right to the city, understood as a collective right of the inhabitants of urban areas, as distinct agenda of urban social movements claim, social actors and collective subjects engaged in the democratization of material and symbolic goods produced and experienced in cities. Such events are intertwined with the emergence of the right to the city, understood as a collective right of the inhabitants of urban areas, as a claim agenda of distinct urban social movements, social actors and collective subjects engaged in the democratization of material and symbolic goods produced and experienced in cities.
\end{abstract}

Keywords: Right to the city, citizenship, riots, social function of the city, fundamental rights. 
INTRODUÇÃO

O ano de 2013 entrará para a História do Brasil como o ano das "Manifestações de Junho". A narrativa daqueles eventos, bem como a interpretação sobre os fatos ocorridos naquele período, no entanto, não será unívoca. De fato, o significado das mobilizações de massa promovidas em várias cidades brasileiras em junho e julho de 2013, ainda está em disputa. O presente artigo procura produzir uma análise daqueles acontecimentos históricos à luz de uma hipótese de pesquisa: as manifestações de junho de 2013 marcaram a emergência do direito à cidade na esfera pública brasileira, exigindo sua efetividade como direito coletivo dos habitantes das cidades, conquistado no bojo do processo histórico de construção dos direitos de cidadania no Brasil.

Tal hipótese de pesquisa, formulada em dezembro de 2013 a fim de orientar uma investigação científica realizada ao longo de 2014, entretanto, tornou-se cada vez menos evidente e mais problematizada, conforme avançavam os acontecimentos de 2014, muito particularmente a realização da Copa do Mundo FIFA e as eleições presidenciais do mesmo ano. O advento de tais fatos lançou novas luzes sobre os eventos de junho, introduzindo no debate a respeito do tema distintas perspectivas analíticas, algumas claramente manipulatórias dos acontecimentos e outras contendo maior poder explicativo do fenômeno.

Passemos, então, à análise dos fatos e das conclusões alcançadas em uma pesquisa de caráter interdisciplinar que envolveu autores da Sociologia, do Urbanismo, da Antropologia, da Geografia e do Direito Urbanístico. A perspectiva interdisciplinar da análise foi fundamental para permitir uma compreensão mais ampla dos fenômenos analisados e o marco teórico da investigação, apresentado ao longo do artigo, foi selecionado a partir das necessidades epistemológicas da pesquisa.

\section{AS MANIFESTAÇÕES DE JUNHO DE 2013}

Em uma análise retrospectiva, sete características interligadas merecem ser destacadas como importantes para a compreensão dos eventos de junho de 2013 no Brasil: (i) a articulação em rede e marcada pela horizontalidade; (ii) a ausência de lideranças porta-vozes únicos do movimento; (iii) o dado de que a reivindicação "gatilho" das manifestações - o valor da tarifa de ônibus - está intrinsecamente vinculada ao direito à cidade; (iv) a progressiva diversificação de pautas; (v) a surpreendente adesão de diferentes setores sociais aos eventos convocados pelas redes sociais; (vi) o caráter nacional, considerando que manifestações foram observadas em mais de 200 cidades brasileiras; (vii) a força simbólica dos eventos de rua, capaz de arrancar respostas 
dos poderes públicos em diferentes esferas de governo. Cabem aqui alguns comentários a respeito desses traços descritivos do fenômeno.

Não há como negar que as manifestações de junho de 2013 foram um marco no que diz respeito à forma tradicional de convocação de protestos, passeatas e atos públicos no Brasil. Os antigos panfletos de papel distribuídos de mão em mão foram substituídos definitivamente pela convocação de eventos em redes sociais, o que, apesar de ser natural para o período em que vivemos, não deixa de portar, no caso, certa ironia. Neste milênio, contesta-se o poder por dentro de ferramentas importantes para a manutenção do próprio poder. O facebook - motor das mobilizações contra o poder econômico das empresas que monopolizam o transporte público nas cidades brasileiras e transformam o direito de ir e vir em mercadoria - é, sabidamente, bastante utilizado como plataforma de publicidade das maiores empresas que concentram o poder econômico do mundo globalizado sob a égide do capitalismo. Castells ${ }^{9}$ chama o fenômeno de contrapoder e o atribui ao fato de que as sociedades, por serem conflitivas e contraditórias, permitem a emergência de nichos de utilização das redes, por exemplo, para a construção e o fortalecimento de movimentos de contracultura e, poderíamos dizer, de movimentos contra hegemônicos, para utilizar a linguagem de Boaventura de Souza Santos ${ }^{10}$.

Alguns dos atores que lideraram as manifestações fizeram questão de marcar a direção coletiva de sua atuação, recusando a indicação de representantes únicos ou de "dirigentes" no sentido politico tradicional. Esse é o caso do Bloco de Lutas, em Porto Alegre, e do movimento Passe Livre, em São Paulo. Tal concepção de mobilização e luta acaba desaguando em uma forte crítica ao sistema político de representação no Brasil e cartazes como não me representa passam a estar fortemente presentes nas mobilizações, em um claro sinal de desaponto com os membros especialmente do Poder Legislativo.

Em relação ao conteúdo das manifestações, pode-se afirmar com segurança que os eventos de 2013 começaram com uma pauta centrada na questão do direito ao transporte público. Porto Alegre foi uma das primeiras a participar da onda coletiva que tomou conta de mais de 200 cidades brasileiras. De acordo com Alfonsin ${ }^{11}$ :

A onda de manifestações eclodiu em função do aumento da passagem de ônibus intraurbano daquela cidade, em vinte centavos [a passagem aumentou de $R \$ 2,85$ para $R \$ 3,05$ ]. Pode parecer pouco, mas a mobilização popular contra o aumento foi imediata. Além das

\footnotetext{
${ }^{9}$ CASTELLS, Manuel. Redes de indignação e esperança. Rio de Janeiro: Zahar. 2013.

10 SANTOS, Boaventura de Sousa. Dilemas do nosso tempo: globalização, multiculturalismo e conhecimento. Entrevista com Boaventura de Sousa Santos. in Curriculo sem fronteiras. V.3. n.2.pp. 5-23, Jul-Dez.2003.

${ }^{11}$ ALFONSIN, Betânia. As vozes da cidade nas manifestações de 2013 e a emergência do direito à cidade. (no prelo)
} 
manifestações de rua convocadas primeiramente pelo Bloco de Lutas pelo Transporte Público, o TJRS reconheceu que o aumento era abusivo e manteve a liminar concedida pelo Juiz Hilbert Maximiliano Obara, da 5a Vara da Fazenda Pública, em Ação Popular, fazendo a tarifa retornar ao patamar anterior.

Note-se que a agenda da redução da tarifa traz em seu bojo a questão do direito que os cidadãos e cidadãs têm à liberdade de circulação pela cidade, ao direito de ir e vir bem como a desfrutar do espaço público como bem coletivo. Quando a passagem de ônibus é muito cara, é o próprio direito à cidade que se torna uma mercadoria. Conforme veremos, o direito à cidade inclui o direito ao transporte e à mobilidade, dentre outros tantos direitos a serem exercidos livremente nos territórios e foi esse conjunto de direitos que foi defendido pelos manifestantes.

Naquele momento histórico de 2013, apoiada pela articulação via rede, a mobilização de rua em Porto Alegre se massificava dia após dia. Não é só pelos vinte centavos, dizia um dos cartazes, em meio a centenas deles espalhados pelas ruas na busca da revogação do aumento da passagem do transporte público. Começaram a multiplicar-se as pautas e eventos públicos para muito além do controle dos governos e dos atores políticos tradicionais, para perplexidade da mídia hegemônica e do senso comum.

A partir da eclosão política da indignação com o aumento da passagem de um sistema de transporte público caro e ineficiente, emergiram dezenas de reivindicações ligadas à qualidade dos serviços públicos analisados em uma perspectiva mais ampla. Educação, saúde e ética na política entraram na agenda em uma conjuntura que colocava as obras preparatórias para a Copa de 2014 no centro do noticiário televisivo. O contraste entre os gastos públicos com os megaeventos ${ }^{12}$ e a precariedade dos serviços públicos, garantidores de direitos fundamentais inscritos na Constituição Federal, foi evidenciado pelos manifestantes de todo o país, em uma crítica social poderosa traduzida em um movimento de massas inédito no Brasil. Pouco a pouco houve uma diversificação surpreendente das pautas, reveladora tanto da existência de inúmeras insatisfações sociais reprimidas quanto dos riscos de um "movimento" sem direção política clara. De fato, setores ligados à direita mais conservadora não tardaram a se fazer presentes nas manifestações, tornando o cenário perigoso em termos políticos, já que o rechaço a partidos políticos, pauta manifestamente fascista, passou a frequentar cartazes com a mesma naturalidade que as reivindicações originais pela redução do preço da passagem.

\footnotetext{
12 Entre 2013 e 2016 o Brasil é palco de três megaeventos esportivos: a Copa das Confederações FIFA, entre 15 e 30 de junho de 2013; a Copa do Mundo FIFA de 2014, entre 12 de junho e 13 de julho de 2014 e, finalmente, os Jogos Olímpicos de 2016, que ocorrerão na cidade do Rio de Janeiro entre 05 e 21 de agosto de 2016.
} 
Se as palavras de ordem se multiplicavam, óbvia e proporcionalmente incrementava-se a diversidade do público presente, bem como o número de pessoas que aderiam a cada convocação para as passeatas e atos públicos. A resposta estatal não tardou e contou com episódios de extrema violência por parte das polícias locais ao reprimir o avanço das massas. Eventos mais violentos ocorridos em São Paulo, inicialmente, foram amplamente divulgados e explorados pela mídia sensacionalista tentando deslegitimar a iniciativa popular, rotulando todos os movimentos como adeptos do vandalismo do patrimônio público e privado, liderados por táticas Black Blocs ${ }^{13}$, reduzindo assim a composição política, social e ideológica dos atores e práticas do período.

O fenômeno da diversificação descontrolada das pautas que originavam os protestos ${ }^{14} \mathrm{fez}$ com que os próprios sujeitos coletivos que deram início aos atos públicos recuassem, demonstrando seu estranhamento com o rumo das manifestações. No entanto, a força simbólica que as mesmas tiveram é inequívoca e pode ser, de certa forma, medida pelas respostas dadas pelo poder público.

Além de Porto Alegre, mais de 100 cidades brasileiras se viram forçadas a reduzir a tarifa do transporte público. ${ }^{15}$ No Congresso Nacional, projetos de lei que claramente implicavam em retrocesso social, como o da "Cura Gay", foram rechaçados rapidamente durante os protestos de junho. Estando em ano pré-eleitoral e às vésperas da realização de um megaevento esportivo, a primeira resposta oficial estatal veio em forma de discurso enfático da Presidente da República, ao lançar um pacto nacional com cinco pontos principais de ação (responsabilidade fiscal, reforma política, saúde, educação e transporte) a ser desenvolvido conjuntamente com os 27 Estados da Federação.

Em resposta à demanda inicial das manifestações, maior qualidade do transporte público, o governo prometeu investimentos com foco também na melhoria da mobilidade urbana em montante que poderia chegar a R\$ 50 bilhões de reais. Porém, após a Copa do Mundo foi

\footnotetext{
${ }^{13} \mathrm{~A}$ ideologia Black Bloc, adepta da estratégia anarquista, baseia-se no questionamento da "ordem vigente", sendo contra o capitalismo e a globalização. Os grupos costumam participar de manifestações de rua com táticas que afrontam a propriedade privada, como forma de expressar seu repúdio ao status quo capitalista.

${ }^{14}$ André Singer catalogou alguns dos slogans escritos nos cartazes caseiros produzidos pelos manifestantes: "Copa do Mundo eu abro mão, quero dinheiro pra saúde e educação", "Queremos hospitais padrão Fifa", "O gigante acordou", "la ixcrever augu legal, maix fautô edukssão", "Não é mole, não. Tem dinheiro pra estádio e cadê a educação", "Era um país muito engraçado, não tinha escola, só tinha estádio", "Todos contra a corrupção", "Fora Dilma! Fora Cabral! pt = Pilantragem e traição", "Fora Alckmin", "Zé Dirceu, pode esperar, tua hora vai chegar". Ver SINGER, André. Brasil, junho de 2013: Classes e ideologias cruzadas. In Novos estudos - CEBRAP no.97 São Paulo Nov. 2013. Disponível em http://www.scielo.br/scielo.php?pid=S0101$33002013000300003 \&$ script=sci_arttext\&tIng=p_Acesso em 15/01/2015.

${ }_{15}$ Ver, a propósito: http://g1.globo.com/brasil/noticia/2013/07/veja-em-quais-cidades-houve-reducao-datarifa-do-transporte-em-2013.html Acesso em 15/01/2015.
} 
divulgado pelo Portal da Transparência que pouco mais de R\$ 8 bilhões foram investidos. ${ }^{16}$ No âmbito da educação foi aprovado o Plano Nacional de Educação que contêm 20 metas a serem alcançadas até 2024 conjuntamente por parte da União, dos Estados e dos Municípios, para melhorar a educação infantil, de jovens e adultos e qualificar os docentes. Em relação à saúde, também uma das grandes reivindicações da população, foi criado o programa Mais Médicos para suprir a carência desses profissionais em regiões onde não havia ou onde o número de profissionais era insuficiente para suprir a demanda. Quanto à responsabilidade fiscal, o anúncio da Presidente pautou garantir a estabilidade da economia e o controle da inflação, tendo como estratégia o combate à corrupção e o mau uso dos recursos públicos ${ }^{17}$. Finalmente, em relação à reforma política, apenas uma minirreforma eleitoral foi aprovada, sem produção de mudanças de fundo no sistema eleitoral brasileiro.

Ainda que as manifestações de junho de 2013 não tenham tido as características de um "movimento", certamente podem ser classificadas como um acontecimento histórico de grande relevância na construção dos direitos de cidadania no Brasil, em função de sua magnitude e das reações que provocaram. A emergência do direito à cidade no cenário jurídico-político brasileiro é um saldo importante das "mobilizações de junho" e passamos agora, a analisar o processo de construção dos direitos de cidadania no Brasil a fim de compreender melhor os elos entre o direito coletivo à cidade e as manifestações.

\section{O PROCESSO DE CONSTRUÇÃO DOS DIREITOS DE CIDADANIA NO BRASIL}

Para compreender o contexto das manifestações de rua é preciso resgatar o que significa o exercício da cidadania no Brasil à luz do processo histórico de negação e de reconhecimento de direitos, o qual se reflete no atual contexto urbano em que diferentes classes e grupos sociais experimentam distintas intensidades de cidadania.

Holston ${ }^{18}$ assinala que no Brasil construiu-se "uma cidadania que administra as diferenças sociais legalizando-as de maneira que legitimam e reproduzem a desigualdade", pois há regimes de privilégios legalizados e desigualdades legitimadas, como no início da República em que a educação não era estabelecida como direito e o analfabetismo e o gênero eram utilizados como barreira para

\footnotetext{
${ }^{16}$ Ver, a propósito, http://www.portaltransparencia.gov.br/copa2014/empreendimentos/tema.seam?tema=8 Acesso em 16/01/2015.

17 Como se sabe, tal anúncio não foi capaz de impedir escândalos recentes de corrupção em empresas estatais como a Petrobras, mas pode-se apontar como positiva a profundidade das investigações ocorridas no período e a inédita prisão de corruptores ligados à indústria da construção civil, em acontecimento inédito no país.

18 HOLSTON, James. Cidadania insurgente: disjunções da democracia e da modernidade no Brasil. São Paulo, Companhia das Letras, 2013, p.22.
} 
uma efetiva cidadania política. O autor define essa formulação de cidadania diferenciada, que se funda na distinção e não na equiparação de tipos de cidadãos, incluindo universalmente, entretanto, sendo fortemente desigual na distribuição de direitos. Durante a vigência da Constituição de 1824, por exemplo, legalmente, o analfabeto poderia votar, no entanto, este direito foi negado expressamente pela Constituição de 1891 em seu artigo 70, parágrafo 1ํ, 2ํ.. No Brasil, temos uma lacuna histórica de participação popular na tomada de decisões, como na Independência e na Proclamação da República, marcos da história nacional.

O Estado estabeleceu-se no Brasil a partir da escravidão e do extermínio indígena, desta forma a prática autoritária é intrínseca à formação nacional. Furtado ${ }^{19}$ assevera que a distância entre elite e povo foi o traço marcante do quadro cultural que surgiu como forma de progresso no Brasil (grifo do autor). Carvalho ${ }^{20}$ afirma que com a Independência o "país herdou a escravidão, que negava a condição humana do escravo, herdou a grande propriedade rural, fechada à ação da lei, e herdou um Estado comprometido com o poder privado". Tais elementos de nosso passado devem ser relembrados para um entendimento mais compreensivo das relações e das estruturas de poder que moldam nosso desenvolvimento político, jurídico, social, econômico e institucional e, consequentemente, a construção e a prática da cidadania.

A formação e positivação dos direitos de cidadania dependem das formas de acesso e influência de diversos grupos nas decisões do Legislativo, do Executivo e do Judiciário para sua incorporação e efetividade. Carvalho ${ }^{21}$ assinala que o debate político sobre a cidadania entre anarquistas, socialistas e setores próximos ao governo, já no início da República, levou a que as melhorias ocorressem através de alianças com o Estado, caracterizando-se assim uma estadania.

A passagem do tempo por si só não é garantia de melhoria das condições de vida e de um aprimoramento da prática cidadã, muito embora tenha ocorrido uma sucessão cronológica de conquista de direitos na história mundial. Primeiramente, com os direitos individuais de liberdades políticas e civis e de participação política (direitos de primeira geração), garantidos em meio às revoluções burguesas do século XVII e XVIII22. Posteriormente, a positivação dos direitos sociais, culturais e econômicos, no início do século XX. Apesar da inclusão normativa, sua efetividade foi

\footnotetext{
19 FURTADO, Celso. O longo amanhecer: reflexões sobre a formação do Brasil. Rio de Janeiro, Paz e Terra, 1999, p. 64.

${ }^{20}$ CARVALHO, José Murilo de. Cidadania no Brasil: o longo caminho. Rio de Janeiro, Civilização Brasileira, 2014, p. 50 .

${ }^{21}$ Idem, p. 66.

2222 SARLET, Ingo W. Os direitos fundamentais sociais na Constituição de 1988. Disponível em: http://www.direitopublico.com.br/pdf_seguro/revista-dialogo-juridico-01-2001-ingo-sarlet.pdf Acesso em 10/02/2015.
} 
falha no Brasil, que manteve ao longo do seu processo histórico discriminações estruturais e legitimadas na distribuição substantiva dos direitos ${ }^{23}$.

Atualmente, a cidadania na cidade é um desafio cada vez mais pungente. Isso porque, além de ser a cidade o lugar da vivência da cidadania, tem-se outro fator que é o projeto políticoeconômico de organização e gestão do território que não proporciona acesso igualitário entre os cidadãos aos serviços públicos, devido a alianças escusas entre Estado e Mercado. Conforme Vainer ${ }^{24}$, "na cidade, como na sociedade em geral, a intervenção do Estado é vista como algo nefasto, que inibe o livre jogo das forças do mercado, que pelos cânones do liberalismo econômico asseguraria a alocação ótima dos recursos".

Milton Santos ${ }^{25}$ já atentava para essa dinâmica e seus impactos na configuração urbana:

A atividade econômica e herança social distribuem os homens desigualmente no espaço, fazendo com que certas noções consagradas, como a rede urbana ou a de sistema de cidades, não tenham validade para a maioria das pessoas, pois o seu acesso efetivo a bens e serviços distribuídos conforme a hierarquia urbana depende do seu lugar socioeconômico e também do seu lugar geográfico.

A lógica perversa que funciona na cidade é a mesma que sempre ocorreu no cenário rural: a da concentração de terra e da alta valorização monetária da terra urbanizada. Conforme Furtado ${ }^{26}$ :

As instituições que permitem a concentração em poucas mãos da formidável valorização das terras urbanas respondem pela miserabilidade de grandes massas da população. A pobreza maciça, característica do subdesenvolvimento, com frequência tem origem numa situação de privação do acesso à terra e à moradia.

Pobreza e subcidadania, portanto, têm ligação direta com questões ligadas à dificuldade de acesso à moradia adequada e a todos os outros serviços essenciais para a vida urbana, caracterizando a negação do direito à cidade.

A sociedade, no entanto, não assiste passivamente ao ver tamanha desigualdade a ser enfrentada no seu cotidiano, de forma a lesar seus direitos sociais mais básicos como o direito à moradia, à mobilidade urbana, à saúde e ao trabalho. O que se percebe no cenário brasileiro é que

\footnotetext{
${ }^{23}$ HOLSTON, James. Cidadania insurgente: disjunções da democracia e da modernidade no Brasil. São Paulo, Companhia das Letras, 2013, p. 28.

${ }^{24}$ VAINER, Carlos. Quando a cidade vai às ruas. In: Cidades Rebeldes. Passe livre e manifestações que tomara o Brasil. São Paulo: Boitempo, 2013, p. 38.

${ }^{25}$ SANTOS, Milton. O Espaço do Cidadão. São Paulo, Edusp, 2012, p. 11.

${ }^{26}$ FURTADO, Celso. O longo amanhecer: reflexões sobre a formação do Brasil. Rio de Janeiro, Paz e Terra, 1999, p. 33.
} 
após a positivação dos direitos sociais e o avanço no investimento em políticas sociais, notou-se a insuficiência dessas medidas, pois a classe trabalhadora segue sendo discriminada no acesso aos serviços públicos essenciais.

Para Holston ${ }^{27}$, analisando o caso de São Paulo como ilustrativo do processo de urbanização brasileiro, as classes trabalhadoras, a partir da construção de suas próprias moradias "assumiram as identidades sem precedentes de produtores e consumidores da vida urbana" e assim, "na condição de construtores da cidade, eles passaram a se compreender como portadores de interesses na cidade, como contribuidores fundamentais para sua economia e sua sociedade ${ }^{28 \prime \prime}$ levando à exigência de novos direitos, ao encontro da afirmativa de Harvey ${ }^{29}$ de que o direito à cidade não é somente direito de acesso ao que já existe, e sim direito ativo de fazer a cidade diferente.

Além dessa compreensão de sujeito de direitos, a condição gerada pelas políticas sociais que levou muitos brasileiros a saírem da linha da miséria nos últimos dez anos ${ }^{30}$ também fortalece os sujeitos que passam a demandar mais além do mínimo existencial. É neste sentido o entendimento de Carvalho ${ }^{31}$ sobre as manifestações de junho de 2013: "mais renda significa também aumento de expectativas e da consciência cidadã, vista esta como percepção mais clara e ampla de direitos".

Bello ${ }^{32}$, ao analisar a concepção de cidadania social marxiana conclui que:

Há dois posicionamentos distintos quanto à potencialidade da cidadania social em viabilizar uma cidadania plena, ou seja a emancipação humana indicada por Marx. Por um lado, tem-se uma posição cética, que denuncia um efeito anestésico gerado no pensamento de esquerda pela cidadania social e sua lógica de funcionamento no Welfare State. Por outro, tem-se um posicionamento que reforça a importância dos direitos sociais (e dos argumentos de Marshall sobre as necessidades básicas) para a teoria socialista e a busca pela ampliação da cidadania democrática.

Advoga o autor pela necessidade de se abandonar a perspectiva estadocêntrica e de se apostar na sociedade civil como novo sujeito e espaço da cidadania, defendendo uma cidadania para além do Estado. A crítica de Bello é pertinente e necessária. Entretanto, em um país tão

\footnotetext{
27 HOLSTON, James. Cidadania insurgente: disjunções da democracia e da modernidade no Brasil. São Paulo, Companhia das Letras, 2013, p. 27.

${ }^{28}$ Idem, p. 27

29 HARVEY, David. A liberdade da cidade. In: Ermínia Maricato (et al.) Cidades rebeldes: Passe Livre e as manifestações que tomaram as ruas do Brasil. 1a ed. São Paulo: Boitempo: Carta Maior, 2013, p. 33.

30 Ver, a propósito: http://www.mds.gov.br/saladeimprensa/noticias/2013/janeiro/brasil-sem-miseria-avancana-reducao-da-extrema-pobreza. Acesso em 12/02/2015

${ }^{31}$ CARVALHO, José Murilo de. Cidadania no Brasil: o longo caminho. Rio de Janeiro, Civilização Brasileira, 2014, p. 11.

${ }^{32}$ BELLO, Enzo. A cidadania na luta política dos movimentos sociais urbanos. Caxias do Sul, Educs, 2013, p. 88.
} 
complexo e desigual, que somente na década de 1930 lançou as bases da sua modernização institucional de maneira mais incisiva, a presença do Estado como ator fundamental é especialmente necessária para aqueles que estão à margem da organização e do acesso aos serviços públicos. Em diferentes momentos históricos, foi e ainda é imprescindível que movimentos sociais, academia, organizações não governamentais e sociedade civil como um todo exerçam pressão pra que o Estado crie condições para que a cidadania seja realmente universal.

\section{O DIREITO À CIDADE}

A própria construção do conceito de direito à cidade advém do questionamento das desigualdades históricas produzidas em âmbito urbano, bem como da reivindicação de setores as sociedade civil ao acesso e à distribuição dos recursos urbanos. Dessa forma, ao buscar meios efetivos de participação no planejamento e na gestão das cidades, os segmentos relacionados à reforma urbana pleiteiam, também, perante o Estado, condições para um exercício concreto da cidadania. Assim, para compreender de forma mais ampla as interfaces entre cidade e cidadania, é fundamental resgatar o próprio conceito de direito à cidade.

“Considerar a cidade como a projeção da sociedade no espaço é ao mesmo tempo um ponto de partida indispensável e uma afirmação muito elementar", opina Manuel Castells ${ }^{33}$. A partir dessas palavras, verifica-se que a cidade, sendo compreendida como um organismo vivo, passa pela história marcada por fatos históricos, políticos, religiosos, culturais e econômicos que produzem características em seu espaço, transformando o ambiente e definindo sua configuração ${ }^{34}$.

"O direito à cidade é o paradigma para a observância das funções sociais da cidade", destacou Nelson Saule ${ }^{35}$. Logo, o direito à cidade está baseado na ideia de que o desenvolvimento das funções da cidade é de interesse de todos os seus habitantes. Para a adequada compreensão desse novo direito humano, é fundamental resgatar sua construção histórica.

O conceito de direito à cidade vem sendo construído mundialmente desde a segunda metade do século XX, sendo que a teoria urbana crítica, desenvolvida, inicialmente, por Henri Lefebvre, na década de 60, é considerada como o principal marco de aprofundamento sobre o tema. Essa difícil tarefa de conceituação tem sido trabalhada por intelectuais das mais diversas áreas de conhecimento, como juristas, sociólogos, geógrafos, antropólogos, economistas,

\footnotetext{
${ }^{33}$ CASTELLS, Manuel. A questão urbana. Rio de Janeiro: Paz e Terra, 1983, p. 146.

${ }^{34}$ MELO, Lígia. Direito à Moradia no Brasil. Belo Horizonte: Fórum, 2010, p. 27.

35 SAULE JUNIOR, Nelson. Direito Urbanístico: vias jurídicas das políticas urbanas. Porto Alegre: Fabris, 2007, p. 53.
} 
arquitetos. ${ }^{36}$ Isso se deve principalmente ao crescente aumento da população urbana nesse cenário e seus efeitos gerados aos habitantes das cidades.

Em geral, o acelerado crescimento urbano na América Latina é explicado pela explosão demográfica e, especialmente, pelo êxodo rural. Esse fator iniciou-se e manteve-se em razão da ausência de políticas consistentes de reforma agrária. Dessa forma, a conjugação entre o veloz processo de urbanização e a inexistência de políticas públicas adequadas tem gerados sucessivos processos de exclusão social, crise habitacional, segregação sócio-espacial, violência urbana e degradação ambiental. Nesse sentido, Letícia Osório afirma:

É também verdade que as cidades são hoje lugar de moradia de grande parte dos pobres do mundo, onde os modelos de desenvolvimento e gestão urbanos, implementados contribuem para o aumento da concentração de renda, propriedade e poder, da informalidade nas relações de trabalho e na posse da terra urbana, para a degradação do meio ambiente e para a privatização do espaço público, gerando exclusão e segregação social e territorial ${ }^{37}$.

No Brasil, o processo de urbanização não foi diferente, conforme demonstra Raquel Rolnik:

Em um dos movimentos socioterritoriais mais rápidos e intensos de que se tem notícia, a população brasileira passou de predominantemente rural para majoritariamente urbana em menos de 40 anos (1940-1980). Este movimento, impulsionado pela migração de um vasto contingente de pobres, ocorreu com base em um modelo de desenvolvimento urbano que basicamente privou as faixas de menor renda da população de condições básicas de urbanidade ou de inserção efetiva à cidade. Em cada ponto do território que apresentou grande crescimento e dinâmica urbana, as qualidades urbanísticas se acumulam em um setor restrito, local de moradia, negócios e consumo de uma minoria da população moradora ${ }^{38}$.

A acelerada urbanização brasileira contribuiu significativamente com a produção da pobreza, através da exclusão social e da segregação espacial de determinadas camadas da população. A falta de acesso à moradia e aos recursos urbanos, os obstáculos à participação no planejamento e na gestão das cidades, as desigualdades sociais históricas produzidas no âmbito urbano contribuem para a legitimação da necessidade de existência de um direito à cidade exigível e acessível aos cidadãos que compõem o contexto urbano.

\footnotetext{
${ }^{36}$ Dentre os estudiosos que contribuíram para o tema, destacamos Raquel Rolnik, Ermínia Maricato, Milton Santos, David Harvey, Betânia Alfonsin, Edésio Fernandes, Nelson Saule Júnior.

37 OSÓRIO, Letícia Marques. Direito à Cidade como Direito Humano Coletivo. In: ALFONSIN, Betânia; FERNANDES, Edésio. Direito Urbanístico: estudos brasileiros e internacionais. Belo Horizonte: Del Rey, 2006, p. 195.

${ }^{38}$ ROLNIK, Raquel. Democracia no fio da navalha: limites e possibilidades para a implementação de uma agenda de reforma urbana no brasil. Revista Brasileira de Estudos Urbanos e Regionais, v. 11, n. 2, p.31-50, nov. 2009,p. 32
} 
Desta forma, dada a importância da apropriação do conceito de direito à cidade, bem como compreendendo as disputas geradas em torno das múltiplas interpretações conferidas a este tema, cabe ressaltar algumas tentativas de conceituação elaboradas em diferentes campos de conhecimento.

Lefebvre, em sua obra-manifesto "O Direito à Cidade" concebe este conceito afirmando ser um direito: “(...) à vida urbana, à centralidade renovada, aos locais de encontro e de trocas, aos ritmos de vida e empregos do tempo que permitem o uso pleno e inteiro desses momentos e locais ${ }^{39 \prime \prime}$. Nesse sentido, o autor também menciona:

O direito à cidade não pode ser concebido como um simples direito de visita ou de retorno às cidades tradicionais. Só pode ser formulado como direito à vida urbana, transformada, renovada. Pouco importa que o tecido urbano encerre em si o campo e aquilo que sobrevive da vida camponesa conquanto que "o urbano", lugar de encontro, prioridade do valor de uso, inscrição no espaço de um tempo promovido à posição de supremo bem entre os bens, encontre sua base morfológica, sua realização prático-sensível ${ }^{40}$.

Peter Marcuse, ao interpretar os escritos de Lefebvre, sustenta que, para tal autor, o direito à cidade consiste em uma reivindicação, uma demanda por uma sociedade diferente, pela criação de uma nova urbe. Marcuse ${ }^{41}$ então aborda o conceito de direito à cidade em Lefebvre como o direito à liberdade de todos à satisfação de seus desejos próprios com todo o apoio necessário para tanto.

Nesse sentido, seguindo os pressupostos da sociologia urbana introduzidos por Lefebvre, David Harvey avança na conceituação do direito à cidade trazendo este como um direito de transformação. Nas palavras do autor:

O direito à cidade é muito mais que a liberdade individual de ter acesso aos recursos urbanos: é um direito de mudar a nós mesmos, mudando a cidade. Além disso, é um direito coletivo, e não individual, já que essa transformação depende do exercício de um poder coletivo para remodelar os processos de urbanização. A liberdade de fazer e refazer as nossas cidades, e a nós mesmos, é, a meu ver, um dos nossos direitos humanos mais preciosos e ao mesmo tempo mais negligenciados ${ }^{42}$.

David Harvey igualmente relaciona o direito à cidade a um direito de criação de cidades que satisfaçam as necessidades humanas. Ele afirma que historicamente as cidades têm sido

\footnotetext{
39 LEFEBVRE, Henri. O Direito à Cidade. 5. ed. São Paulo: Centauro Editora, 2008, p. 139.

40 IBIDEM, p, 118.

${ }^{41}$ MARCUSE, Peter. Os direitos nas cidades e o direito à cidade? In: HABITAT INTERNATIONAL COALITION (Org.). Cidades para tod@s: Propostas e experiências pelo direito à cidade. Santiago: Ana Sugranyes e Charlotte Mathivet, 2010.

42 HARVEY, David. A liberdade da cidade. In: Ermínia Maricato (et al.) Cidades rebeldes: Passe Livre e as manifestações que tomaram as ruas do Brasil. 1a ed. São Paulo: Boitempo: Carta Maior, 2013.
} 
regidas mais pelo capital do que pelas próprias pessoas, e, portanto, afirma que na luta pelo direito à cidade haverá também uma luta contra o capital ${ }^{43}$.

Para melhor compreensão do tema, além de tais abordagens teóricas, destaca-se igualmente a elaboração da Carta Mundial pelo Direito à Cidade ${ }^{44}$, documento de grande importância para a compreensão da cidade e de suas funções como um direito do cidadão. Já nas primeiras linhas, a Carta declara que "todas as pessoas devem ter o direito a uma cidade sem discriminação de gênero, idade, raça, condições de saúde, renda, nacionalidade, etnia, condições migratórias, orientação política, religiosa ou sexual.".

Esse documento entende o direito à cidade como "o usufruto equitativo das cidades dentro dos princípios de sustentabilidade, democracia, equidade e justiça social. É um direito coletivo dos habitantes das cidades, em especial dos grupos vulneráveis e desfavorecidos." (art. $1^{\circ}$, II). Compreende, portanto, o direito à cidade como interdependente de todos os outros internacionalmente reconhecidos. Logo, está fortemente vinculado aos direitos civis, políticos, econômicos, sociais, culturais e ambientais.

A Carta Mundial identifica, ainda, duas acepções para o conceito de cidade. A primeira está relacionada ao aspecto físico pelo qual a cidade é toda metrópole, urbe, vila ou povoado que esteja organizado institucionalmente como unidade local de governo de caráter municipal ou metropolitano. A segunda está vinculada ao espaço político pelo qual a cidade é o conjunto de instituições e de atores que intervém em sua gestão, tais como autoridades governamentais, legislativas, judiciárias; instâncias de participação social institucionalizadas; movimentos, organizações sociais e a comunidade em geral ${ }^{45}$.

A Carta apresenta, também, medidas que devem ser adotadas para a implementação e a supervisão do direito à cidade, as quais devem basear-se na máxima utilização dos recursos disponíveis e na implementação de direitos humanos previstos nas legislações nacionais e internacionais ${ }^{46}$. Dessa forma, a Carta Mundial é um importante documento político que tem por objetivo disseminar o direito à cidade como um novo direito humano, visando modificar a

\footnotetext{
${ }^{43}$ HARVEY, David. Alternativas ao neoliberalismo e o direito à cidade. Novos Cadernos Naea, Belém, v. 12, n. 2, p.269-274, dez. 2009, p. 270.

${ }^{44}$ A Carta Mundial pelo Direito à Cidade, elaborada durante os Fóruns Sociais Mundiais, teve por subsídio a Carta Europeia dos Direitos Humanos na Cidade, o Tratado "Por cidades, Vilas e Povoados, Justos, Democráticos e Sustentáveis" e a plataforma brasileira do direito à cidade e a reforma urbana. O documento foi reconhecido pelo Brasil em 2005, no Fórum Social Mundial, em Porto Alegre.

${ }^{45}$ MELO, Lígia. Direito à Moradia no Brasil. Belo Horizonte: Fórum, 2010, p. 32.

46 OSÓRIO, Letícia Marques. Direito à Cidade como Direito Humano Coletivo. In: ALFONSIN, Betânia; FERNANDES, Edésio. Direito Urbanístico: estudos brasileiros e internacionais. Belo Horizonte: Del Rey, 2006, p. 197.
} 
realidade urbana mundial através da construção de cidades justas, humanas, democráticas e sustentáveis ${ }^{47}$.

No Brasil, a trajetória de reconhecimento do direito à cidade como direito fundamental está fortemente vinculada às lutas sociais pela reforma urbana. Durante a Assembleia Nacional Constituinte - a qual elaborou a Constituição Federal de 1988 -, o Fórum Nacional de Reforma Urbana apresentou a Emenda Popular de Reforma Urbana, que, em seus 21 (vinte e um) artigos, propunha a autonomia do governo municipal; a função social da propriedade e da cidade, bem como o combate à retenção especulativa do solo; direito social à moradia; gestão democrática das cidades; a justa distribuição dos bens e serviços urbanos. As reivindicações foram parcialmente aprovadas e resultaram nos artigos 182 e 183 da Constituição Federal, reunidos no capítulo Da Política Urbana ${ }^{48}$.

O direito à cidade foi uma grande marca política do texto constitucional de 1988, afastando-se da visão tacanha e conservadora da urbe como um bem econômico. Embora a Emenda Popular tenha sido reduzida a dois artigos, o capítulo Da Política Urbana criou um marco histórico centrado em ideias de justiça social e cidadania, prevendo o desenvolvimento sustentável e preceituando instrumentos para que a propriedade privada e a pública pudessem atender as necessidades sociais ${ }^{49}$.

A inclusão do direito à cidade no rol dos direitos fundamentais garantiu legitimidade para exigir iniciativas do Poder Público e resultou na possibilidade de contrapor-se às tentativas do processo contemporâneo de acúmulo privado de capital em detrimento das condições de vida digna da maioria da populaçã $0^{50}$. Neste sentido, "o reconhecimento do direito à cidade como

\footnotetext{
${ }^{47}$ SAULE JUNIOR, Nelson. Direito Urbanístico: vias jurídicas das políticas urbanas. Porto Alegre: Fabris, 2007, p. 39.

${ }^{48}$ ALFONSIN, Betânia; FERNANDES, Edésio. Coletânea de Legislação Urbanística: normas internacionais, constitucionais e legislação ordinária. Belo Horizonte: Fórum, 2010, p. 17

${ }^{49}$ MELO, Lígia. Uma Análise sobre o Capítulo da Política Urbana na Constituição de 1988. Porto Alegre: Revista Magister de Direito Ambiental e Urbanístico. N¹9. 2008, p.57.

50 Para Sarlet, os direitos fundamentais são aqueles direitos do ser humano que são reconhecidos e positivados na esfera do direito constitucional positivo de um determinado Estado, portanto, são direitos que possuem um caráter nacional (SARLET, Ingo Wolfgang. A eficácia dos direitos fundamentais. 6a ed. Porto Alegre: Livraria do Advogado, 2006, p. 35 e 36). Dessa forma, o autor define os direitos fundamentais como sendo todas as posições jurídicas relativas às pessoas, as quais, sob a ótica do direito constitucional positivo, foram, por seu conteúdo e importância (fundamentalidade em sentido material), integradas ao texto constitucional e retiradas da esfera de disponibilidade dos poderes constituídos (fundamentalidade formal), bem como aquelas que, por seu conteúdo e significado, possam ser equiparadas a direitos fundamentais, agregando-se à Constituição material, possuindo ou não assento na Constituição formal, considerando-se, por exemplo, a abertura material do Catálogo (artigo 5o, da Constituição Federal) (SARLET, citado por PRESTES, 2006, p. 56 e 57).
} 
direito humano fundamental é condição expressivamente imperativa, que pressupõe uma atividade constitucional (forma) e outra institucional (agir governamental) efetivas" ${ }^{11}$.

A responsabilidade definida na Constituição e a afirmação do direito à cidade conduziram à consolidação de um novo ramo do direito público: o direito urbanístico. Esse sistema é composto por um conjunto próprio de regras e princípios que reconhecem e juridicizam o direito das pessoas que habitam as cidades - amparando o direito de viver dignamente ${ }^{52}$. Assim, após a promulgação do texto constitucional, foi sancionada a Lei $n^{\circ} 10.257 / 2001$, conhecida como Estatuto da Cidade, que se transformou no eixo para a regulamentação do capítulo Da Política Urbana e na basemestre do ordenamento urbanístico brasileiro.

O direito à cidade não é um conceito fechado em si mesmo. Como lembra Vanesca Prestes $^{53}$, o direito à cidade é um direito em construção, que se solidificou com a Constituição de 1988 e com a nova ordem jurídico-urbanística.

Dessa forma, como refere a autora, no Estado Socioambiental Democrático de Direito, o conceito de cidade engloba o princípio da dignidade da pessoa humana, bem como a expressão da democracia e da cidadania, resultando em cidades cidadãs e democráticas, havendo espaço para a manifestação (e a vivência) das diferenças. Logo, compreende-se que a cidade tem o dever de: ter um compromisso com a prática constitucional, tendo por norte o princípio da dignidade da pessoa humana; preocupar-se, respeitar e ter em sua política pública a observância à sustentabilidade urbano-ambiental, pois a cidade como meio ambiente não é uma política setorial de um órgão público; dar legitimidade jurídica à propriedade, observando a função socioambiental determinada pelo Plano Diretor; ser democrática; oferecer um espaço para o exercício da cidadania e da expressão das diferenças.

Observa-se, portanto, que o conceito de direito à cidade é amplo. Ao mesmo tempo em que está relacionado à satisfação das necessidades básicas de todo o ser humano habitante da urbe, tais como moradia adequada e acesso a serviços e infraestrutura urbana; está, também, conectado à existência de possibilidades de participação efetiva da população na gestão e na construção da cidade. Nesse sentido, o envolvimento e o engajamento dos indivíduos no espaço em que habitam são essenciais para a concretização dos seus direitos de cidadania e, consequentemente, para a realização de uma cidade efetivamente democrática.

\footnotetext{
${ }^{51}$ BALDO, lumar Junior. Direito à cidade: uma possibilidade real a partir do acesso à moradia digna e sua função socioambiental. Curitiba: Multideia, 2012, p. 21.

52 MELO, Op. cit. p. 57.

53 PRESTES, Vanêsca Buzelato. Dimensão Constitucional do Direito à Cidade e Formas de Densificação no Brasil. Programa de Pós-Graduação em Direito (Dissertação de Mestrado). Porto Alegre: PUCRS, 2008,p. 52 e 53.
} 


\section{CONCLUSÕES}

A análise das manifestações de junho de 2013, realizada com um distanciamento temporal de um ano e meio, permite compreender melhor o significado daquele momento histórico. Da mesma forma, a investigação realizada permite a apresentação de algumas conclusões que articulam o tripé analítico composto pelos eixos (i) manifestações de 2013, (II) processo histórico de construção dos direitos de cidadania no Brasil e (iii) direito à cidade, com a conjuntura vivida pelo Brasil nesse início de 2015.

1. As manifestações de 2013 não foram um episódio isolado na história do país, mas, pelo contrário, ocupam um lugar significativo no processo de construção dos direitos de cidadania, já que marcam a emergência do direito à cidade, enquanto direito coletivo dos habitantes de territórios urbanos, na agenda de reivindicações dos distintos atores sociais que participaram daquele processo;

2. o direito à cidade, conquistado em 2001 quando da aprovação do Estatuto da Cidade, adquire densidade histórica quando os muitos direitos que o compõe são reivindicados nas ruas das cidades, transformadas em arena política e espaço de construção da cidadania plena;

3. o direito à cidade emerge como um feixe de direitos que estabelece forte contraponto à prática capitalista de transformar a cidade e todos os seus bens em mercadoria;

4. os atores e sujeitos coletivos que ocupam as ruas para exigir o direito à cidade, demonstram conhecer os seus direitos, o que tem valor político em si mesmo, podendo ser considerado um exercício de cidadania e de democracia participativa;

5. a forma de organização, mobilização e reivindicação surgida durante as manifestações de 2013, marcadas pela horizontalidade, pela articulação em rede e pelo pluralismo político dos manifestantes, deve tornar-se recorrente no próximo período da história brasileira, constituindo-se em uma espécie de "legado pedagógico" das manifestações;

6. enquanto a pauta da mobilidade urbana e do preço da tarifa dos ônibus intraurbanos marcaram a cena de 2013, novas questões relacionadas ao direito à cidade deverão ser reivindicadas no próximo período, estabelecendo uma espécie de continuidade não linear àquelas manifestações de junho.

A conjuntura nacional no início do ano de 2015 aponta para novos desafios para as cidades brasileiras, como o novo aumento das passagens de ônibus intraurbanos em várias capitais e a crise hídrica vivida pela região sudeste. Tais fatos poderão desencadear novos eventos de massa, semelhantes ou ainda mais contundentes que os verificados em 2013. Novamente devem 
voltar à baila as manifestaçoes que contestam a gestão urbana e as políticas públicas que convertem a própria cidade em mercadoria. Entendemos como possível um cenário de mobilização social que tem como pano de fundo as mesmas questões abordadas pela população durante os protestos de junho de 2013: o direito à cidade sustentável, o direito a desfrutar dos bens materiais e simbólicos que traduzem a idéia de cidade, o direito à justa distribuição dos ônus e benefícios do processo de urbanização, o direito à gestão democrática e à participação nos fóruns em que as decisões relacionadas às políticas urbanas são tomadas. Nesse sentido, o ano de 2015 pode ser um ano chave para a consolidação de uma nova forma de participação popular, de exercício do direito de livre expressão e manifestação, que teve seu início nos eventos de junho de 2013 aqui analisados. Assim, pode-se afirmar que as manifestações de 2013 foram um acontecimento da maior importância tanto para o amadurecimento político de distintos movimentos sociais urbanos, atores sociais e sujeitos coletivos, como para o processo de construção dos direitos de cidadania no Brasil, marcando, em definitivo, a emergência do direito à cidade e de novas formas de protagonismo cidadão na luta por uma cidade para todos e todas.

\section{REFERÊNCIAS}

ALFONSIN, Betânia. As vozes da cidade nas manifestações de 2013 e a emergência do direito à cidade. (no prelo)

ALFONSIN, Betânia; FERNANDES, Edésio. Coletânea de Legislação Urbanística: normas internacionais, constitucionais e legislação ordinária. Belo Horizonte: Fórum, 2010.

BALDO, lumar Junior. Direito à cidade: uma possibilidade real a partir do acesso à moradia digna e sua função socioambiental. Curitiba: Multideia, 2012.

BELLO, Enzo. A cidadania na luta política dos movimentos sociais urbanos. Caxias do Sul, Educs, 2013.

Política, cidadania e direitos sociais: um contraponto entre os modelos clássicos e a trajetória da América Latina. 2007. 153 f. Dissertação (Mestrado em Direito) - Programa de Pós-Graduação em Direito, Pontifícia Universidade Católica do Rio de Janeiro, Rio de Janeiro, 2007. 
BRASIL. Constituição da República Federativa do Brasil de 1988 . In: <http://www.planalto.gov.br/ccivil_03/constituicao/constituicao.htm>. Acesso em 09 de novembro de 2014.

CARVALHO, José Murilo de. Cidadania no Barsil: o longo caminho. Rio de Janeiro, Civilização Brasileira, 2014.

CASTELLS, Manuel. A questão urbana. Rio de Janeiro: Paz e Terra, 1983.

Redes de indignação e esperança. Rio de Janeiro: Zahar. 2013.

FERNANDES, Edésio. A nova ordem jurídico-urbanística no Brasil in: FERNANDES, Edésio; ALFONSIN, Betânia. Direito Urbanístico: estudos brasileiros e internacionais. Belo Horizonte, Del Rey, 2006.

FURTADO, Celso. O longo amanhecer: reflexões sobre a formação do Brasil. Rio de Janeiro, Paz e Terra, 1999.

HARVEY, David. A liberdade da cidade. In: Ermínia Maricato (et al.) Cidades rebeldes: Passe Livre e as manifestações que tomaram as ruas do Brasil. 1a ed. São Paulo: Boitempo: Carta Maior, 2013.

O direito à cidade. Revista Piauí, São Paulo, ed. 82, jul. 2013. Disponível em: <http://revistapiaui.estadao.com.br/edicao-82/tribuna-livre-da-luta-de-classes/o-direito-a-cidade>. Acesso em: 13 nov. 2014.

Alternativas ao neoliberalismo e o direito à cidade. Novos Cadernos Naea, Belém, v. 12, n. 2, p.269-274, dez. 2009.

HOLSTON, James. Cidadania insurgente: disjunções da democracia e da modernidade no Brasil. São Paulo, Companhia das Letras, 2013.

LEFEBVRE, Henri. O Direito à Cidade. 5. ed. São Paulo: Centauro Editora, 2008.

MARCUSE, Peter. Os direitos nas cidades e o direito à cidade? In: HABITAT INTERNATIONAL COALITION (Org.). Cidades para tod@s: Propostas e experiências pelo direito à cidade. Santiago: Ana Sugranyes e Charlotte Mathivet, 2010.

MARICATO, Ermínia. É a questão urbana, estúpido! Cidades Rebeldes: passe livre e as manifestações que tomaram as ruas do Brasil. São Paulo: Boitempo, 2013. 
MELO, Lígia. Uma Análise sobre o Capítulo da Política Urbana na Constituição de 1988. Porto Alegre: Revista Magister de Direito Ambiental e Urbanístico. №19. 2008.

Direito à Moradia no Brasil. Belo Horizonte: Fórum, 2010.

OSÓRIO, Letícia Marques. Direito à Cidade como Direito Humano Coletivo. In: ALFONSIN, Betânia; FERNANDES, Edésio. Direito Urbanístico: estudos brasileiros e internacionais. Belo Horizonte: Del Rey, 2006.

PRESTES, Vanêsca Buzelato. Dimensão Constitucional do Direito à Cidade e Formas de Densificação no Brasil. Programa de Pós-Graduação em Direito (Dissertação de Mestrado). Porto Alegre: PUCRS, 2008.

ROLNIK, Raquel. Democracia no fio da navalha: limites e possibilidades para a implementação de uma agenda de reforma urbana no brasil. Revista Brasileira de Estudos Urbanos e Regionais, v. 11, n. 2, p.31-50, nov. 2009.

SARLET, Ingo W. Os direitos fundamentais sociais na Constituição de 1988. Disponível em: http://www.direitopublico.com.br/pdf_seguro/revista-dialogo-juridico-01-2001-ingo-sarlet.pdf Acesso em 10/02/2015.

SAULE JUNIOR, Nelson. Direito Urbanístico: vias jurídicas das políticas urbanas. Porto Alegre: Fabris, 2007.

SANTOS, Boaventura de Sousa. Dilemas do nosso tempo: globalização, multiculturalismo e conhecimento. Entrevista com Boaventura de Sousa Santos. in Curriculo sem fronteiras. V.3. n.2.pp. 5-23, Jul-Dez.2003.

SANTOS, Milton. O Espaço do Cidadão. São Paulo, Edusp, 2012.

SINGER, André. Brasil, junho de 2013: Classes e ideologias cruzadas. In Novos estudos CEBRAP no.97 São Paulo Nov. 2013. Disponível em http://www.scielo.br/scielo.php?pid=S010133002013000300003\&script=sci_arttext\&tlng=p_ Acesso em 15/01/2015. 
VAINER, Carlos. Quando a cidade vai às ruas. In: Cidades Rebeldes. Passe livre e as manifestações que tomaram as ruas do Brasil. São Paulo: Boitempo, 2013.

Trabalho enviado em 20 de fevereiro de 2015.

Aceito em 25 de fevereiro de 2015. 